\title{
Electronic And Paper Document Retention And Auditors' Responsibilities
}

\author{
Mohamed I. Gomaa, Hofstra University, USA
}

\begin{abstract}
The issue of the destruction of documents raises many ethical and legal problems for the auditing profession. Such an issue needs to be examined more closely to explore its ethical and legal implications, and to address the more technical issue of how to retrieve the destroyed electronic documents. The purpose of this research paper is twofold. The first is to examine the auditors' ethical responsibilities regarding the retention of the electronic and paper documents related to an audit engagement, using the Enron case as a practical case for analysis. The second is to discuss methods of retrieving different types of destroyed electronic documents.
\end{abstract}

Keywords: Document Retention; Retrieving Destroyed Electronic Documents; Auditing Profession

\section{INTRODUCTION}

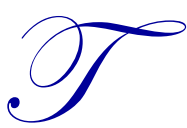

he collapse of Enron Corporation has led many researchers to re-evaluate accounting practices and auditors' ethical responsibilities. A major share of the blame for the collapse of Enron can be attributed to the ethical climate in the company (Verschoor, 2002). The auditors were blamed, too, for some questionable behavior during their engagement and when the scandal became public. One of the major issues in the Enron case is the existence of conflict of interest and its effect on auditors' independence. Such an issue raises questions about the auditors' professional and ethical responsibilities. Another major issue is the destruction of paper and electronic documents. This issue has, not only ethical implications, but might also have some legal consequences.

Many questions arose as a result of the Enron case: First, what is the auditor's ethical responsibility in an audit engagement? Second, in the age of information technology, what is the auditor's responsibility towards the retention and protection of electronic information? Third, when some electronic information is destroyed, how can an auditor retrieve it?

Many research papers have examined the issue of auditor's independence, the auditor's ethical responsibilities, and the ethical decision making process. Guntz and McCucheon (1991), for example, looked at the auditing profession and its understanding of the relationship between independence and conflict of interest. Other studies, (e.g., Au and Wong, 2000; Ford and Richardson, 1994; Jones, 1991; and Ferrel et al., 1989), examined the auditor's ethical responsibilities and the ethical decision making process. These studies, however, are more concerned with modeling the ethical decision-making process, and they do not deal with specific ethical problems like those that emerged in the Enron case. The issue of the destruction of documents raises many ethical and, maybe, legal problems for the auditing profession. Such an issue needs to be examined more closely to explore its ethical and legal implications, and to address the more technical issue of how to retrieve the destroyed electronic documents.

The purpose of this research paper is twofold. The first is to examine the auditors' ethical responsibilities regarding the retention of the electronic and paper documents related to an audit engagement, using the Enron case as a practical case for analysis. The second is to discuss methods of retrieving different types of destroyed electronic documents. The importance of this study stems from the implications of the issues examined on the accounting profession. The remainder of this paper is organized as follows. The next section provides a brief review of prior literature on auditors' ethical responsibilities and their responsibilities towards electronic and paper document retention. Section 3 provides a discussion of the ethical issues related to the auditors' engagement with Enron and the issues related to electronic and paper document retention. Section 4 discusses methods of retrieving destroyed electronic data. Finally, Section 5 provides concluding remarks. 


\section{BACKGROUND}

\subsection{The Ethical Responsibilities of Auditors}

Professional ethics is not only instrumental in the maintenance of a moral, ethical and honest image among the public, it is the only way in which professional bodies can ensure that the empowered trust from society can be upheld (Au and Wong, 2000). As noted by Au and Wong (2000), several researchers have developed a wide range of ethical decision-making models (e.g. Dubinsky and Loken, 1989; Ferrell and Gresham, 1985; Ferrell et al., 1989; Hunt and Vitell, 1986; Jones, 1991; and Treevino, 1986). They noted that one of the common features of these studies is the incorporation of the cognitive moral development process into the theoretical framework of these models. Ford and Richardson (1994), on the other hand, note that while any of these models may serve as a basis for undertaking an empirical study of the ethical decision process, there is limited effort directed toward theory testing. Referring to the four stages of the ethical decision making process presented by Jones (1991) and Ferrel et al (1989): Awareness, cognition, evaluation and intention, Au and Wang (2000) argue that differences in ethical behaviors are affected by the kind of moral thinking that are advanced through the first three stages of the moral development process.

$\mathrm{Au}$ and Wong (2000) suggest that prior research studying the underlying ethical reasoning process of professional accountants in practice suggest the following two findings. First, professional accountants have not reached their potential for higher levels of ethical reasoning (Armstrong, 1987, 1993; Lampe and Finn, 1992; Ponemon, 1990, 1992; Shaub, 1989, 1994). Second, a major determinant of ethical judgment could be ethical reasoning (Arnold and Ponemon, 1991; Peonmon, 1990, 1992; Poemon and Gabhart, 1990; and Tsui, 1996) as well as unethical behavior (Ponemon, 1992).

Auditors have ethical obligations to the shareholders and board of directors for which they are employed (Gunz and McCutcheon 1991). They also have an ethical duty to ensure that the financial statements are fair and appropriate (Gunz and McCutcheon, 1991). An audit, as defined by Lemon et al. (1987), is "the process by which a competent independent person accumulates and evaluates evidence about quantifiable information related to a specific economic entity for the purpose of determining and reporting on the degree of correctness between the quantifiable information and established criteria" (Gunz and McCutcheon 1991, 778). As noted by Gunz and McCutcheon (1991, 778), independence means "taking an unbiased viewpoint in the performance of audit tests, the evaluation of results, and the issuance of the audit report." An auditor's duty to the client and to the public might conflict and may result in circumstances in which the duty to either the client or the public or both might conflict with the auditor's perceived self-interest (Gunz and McCutcheon, 1991).

The issues of conflict of interest and other ethical issues have been recognized by the profession when the AICPA issued its Code of Professional Conduct. This code is meant to provide general standards of ideal conduct and more specific roles of conduct. Most of the ethical problems discussed in the literature, are attributed to violations of some rule of conduct. The two issues that received much of the attention are auditor's independence and the auditor's integrity and objectivity. As noted by Castellano $(2002,2)$, the AICPA "continues to believe that nonaudit consulting services do not compromise a CPA firm's objectivity or independence as long as the required safeguards imbedded in the Code of Professional Conduct are followed." However, in order to restore public confidence in the accounting profession after the Enron case, the largest CPA firms in the United States agreed to impose extraordinary restrictions on the consulting services they offer to their audit clients (Castellano, 2002). The AICPA has also responded to the Enron case by approving "a resolution to support prohibitions that would prevent audit firms from performing systems design and implementations as well as internal audit outsourcing for public audit clients" (Thomas 2002, 9). This was later included as part of the Sarbanes-Oxley Act of 2002.

With respect to internal auditors, Stanford (1991) discusses four tools that may assist auditors in their ethical decision-making. The first is the IIA's Code of Ethics, which was first issued in 1968 then revised in 1988. Its purpose and applicability are stated in philosophical terms followed by eleven standards of conduct. The Standards of Conduct provide basic principles that require internal auditor judgment in their application and stress trust and loyalty to the organization, balanced within legal parameters. The second foundation for ethical thinking is to comply with the Standards for the Professional Practice of Internal Auditing. These standards articulate the best 
practice of internal auditing when one is faced with ethical dilemmas. The third tool to assist auditors in their ethical decision-making is The IIA's position paper on whistle-blowing which stresses the reporting mechanisms available to internal auditors. The fourth resource is consultation with peers, which can be an invaluable tool in ethical dilemmas.

\subsection{Auditors' Responsibilities Towards Electronic and Paper Document Retention}

Organizations' reliance on electronic records has been increasing over the years. Instead of maintaining traditional paper files as official records, information is being created and maintained in electronic format such as e-mails, letters, spreadsheets, databases, and a variety of other potential records (Skupsky, 1999; Fernández-Alemán, 2013). Communication which would have been by telephone ten yeas ago is now routinely being carried out through email, and usually with copies to anybody who might be interested in the subject (Kolar, 2001; Hastings and Payne, 2013). As explained by Kolar (2001), electronic data exists in three separate states: active, archival and residual. Data that is in a personal computer or on the network that is immediately available is active data. Data that has been backed up, which may be able to restore data to a computer system, is archival data. Residual data is the data that many people believe has been deleted but which still remains available to experts. Data is not deleted completely from a system until it has been over-written by new information or "wiped" (Kolar 2001). Hunton (2002) discusses some data-backup-recovery strategies that a firm can adopt to survive a disaster. Such strategies can be used by a CPA firms as well to protect electronic data-documentation. For a large firm that requires high-speed recovery, alternative strategies suggested by Hunton (2002) include the use of BRSP hot site, disk striping, server fortification, network attached storage, storage area network, and distributed processing on multiple servers at onsite location.

Kolar $(2001,284)$ provides the following guidelines for a good retention policy that is set out in detail in Lewy v. Remington Arms Co.:

1. "The length of the retention period should be reasonable for the specific type of document involved, and need not be the same for each type of document."

2. "The frequency and magnitude of lawsuits requiring access to certain types of documents should be considered."

3. "The reason for the adoption of the retention policy can also be important to the reviewing court, because if the retention policy is instituted only in order to limit damaging evidence available to plaintiffs, an "adverse inference" instruction may be proper."

As noted by Howell (2002), every company should review its document retention policies to avoid the potential legal pitfalls. He describes several steps that a company can take to ensure that documents are gathered, retained, and destroyed in a way that protects the company from liability. The first step is that the policy must be claims and litigation neutral. This means that it must be consistently applied without regards to whether the documents will be helpful or damaging in helpful litigation claims. Second, the document should identify all legal requirements. Third, it should address the types of records the company generates, what form these records take, and the requirements of the functions and operations of the organization. Fourth, the policy must include an effective procedure for ensuring that electronic copies of paper records are complete and accurate replicas of the originals and will continue to be accessible in tangible form as long as the record will need to be retained. Fifth, the policy should be designed in coordination with IT staff to establish procedures to ensure effective implementation.

Kolar (2001) notes that the most under-regulated portion of a document retention system is probably e-mail. He also noted that once a lawsuit is filed or there is good reason to believe that one will be filed, the document retention program should include provisions to ensure that any documents that may be relevant to the litigation will be segregated and retained. In this case, the attorney that will represent a firm should work with a designated individual to establish which documents will be preserved and how they will be preserved and stored (Kolar 2001).

The AICPA recognized the need to issue a new auditing standard as a result of the developments in information technology. In January 2002, it issued Statement on Auditing Standards (SAS) no. 96, Audit Documentation, which was later superseded by AU Section 339, then PCAOB Auditing Standard No. 3. This Auditing Standard "requires an auditor to adopt reasonable procedures to retain (audit) documentation long enough to meet the needs of his or 
her practice and to satisfy any applicable legal or regulatory requirement for record retention." (Whittington and Gretchen, 2002, 5). As noted by Whittington and Gretchen (2002), this auditing standard does not specify the length of the retention period. The auditor, however, is required to establish audit procedures that enables him or her to access electronic audit-documentation throughout the retention period. This auditing standard is another step on the right direction to restore confidence in the accounting profession.

\section{THE ENRON DEBACLE REVISITED}

\subsection{Ethical Issues Related to the Auditors' Engagement}

The Enron debacle raised several ethical issues related to the auditor's engagement. One of the major issues related to Arthur Andersen's engagement is the issue of conflict of interest. Arthur Andersen wasn't just the external auditor for Enron, it was also the company's internal auditor (Hilzenrath 2001). As noted by Thomas (2002, 10), Andersen "kept a staff on permanent assignment at Enron's offices." He also noted that "many of Enron's internal accountants, CFOs and controllers were former Andersen executives." (Thomas, 2002, 10). Hilzenrath (2001) states that while performing both roles should have put Andersen in a stronger position to catch the problems that brought down Enron, it might have weakened the advantage of having two levels of safeguards. The result was, Andersen was working on the accounting system and controls with one hand and attesting to the numbers they produce with the other (Byrnes et al. 2002). Lynn E. Turner, former chief accountant of the Securities and Exchange Commission states that when the external auditor also does internal auditing "you have lost not only the checks and balances, you have also lost the voice and perspective of an independent third party" (Hilzenrath 2001, 1). Enron attempted to defend the arrangement by stating "the integrated audit put Andersen in the position to be better informed about Enron. Not only would it have the benefit of audit procedures conducted from the outside, it also would have the benefit of the knowledge gained from serving as the internal auditor" (Hilzenrath 2001, 2). However, the study conducted by Gunz and McCutcheon (1991) suggests that in this situation, an auditor may be faced with a judgment decision, which, if exercised one way, will anger the client seeking out an alternate firm for the full range of accounting services. Therefore, the auditor will be faced with a situation where his duty to the client and the public will conflict with his perceived self-interest.

Other issues that led to a conflict of interest situation include management advisory services performed by Andersen on behalf of Enron. Andersen was richly rewarded \$25 million in audit fees from Enron and \$27 million in consulting fees and other work (Byrnes et al. 2002). Byrnes et al. $(2002,1)$ states that according to a former Andersen officer, "there were so many people in the Houston office who had their fingers in the Enron pie ... if they had someone who said we can't sign this audit, that person would get fired." Other issues, such as having several top executives of Enron as former executives at Arthur Andersen, may have led to violations of auditor's independence resulting in Andersen allowing Enron to follow aggressive accounting practices, violate GAAP and manipulate accounting earnings.

\subsection{Issues Related to Electronic and Paper Document Retention}

One of the major issues in the Enron debacle is the destruction of confidential documents by both Enron and Arthur Andersen. Arthur Andersen admitted to destroying a "significant but undetermined" number of electronic and paper documents that relate to the Enron audit (Reuters 2002). It claims that this was done "in accordance with firm policy." (Thomas 2002, 10). Hebert $(2002,1)$ notes that lawyers at Arthur Andersen directed the destruction of Enron documents when Andersen and executives at Enron "knew that Enron was in real trouble and the roof was about to collapse on them." He also notes that "there's pretty strong evidence of insider trading, there's clear evidence of failure to file honest and correct reports." The investigation shows that there was a coordinated effort to destroy evidence.

Arthur Andersen's policy towards document retention and destruction of documents describes their policy with regard to protecting the confidentiality of client information through its creation, active use to support or defend their work, and destruction. The policies described relate to hard copy and electronic documents and client information used or produced by Andersen personnel in providing arranged services to clients. Andersen did not comply with its document retention and destruction policy and continued to destroy documents after they received 
an SEC subpoena. Andersen's lawyers should have worked with Andersen personnel to establish which documents would be preserved and how they would be preserved and stored. To defend itself, Andersen will have to retrieve some of the electronic documents it destroyed. Andersen hired ASR Data Acquisition \& Analysis of Cedar Park, Texas, an outside computer firm, to assist in the recovery of the destroyed records (McRoberts et al. 2002). According to McRoberts et al. (2002), whether the Enron files that Andersen employees destroyed can be recovered depends on how effective the "shredder" software that Andersen used is.

\section{RETRIEVING DESTROYED ELECTRONIC INFORMATION}

Several businesses and computer programs assist in retrieving destroyed data. Some of these businesses specialize in servicing clients in computer related litigations. Document Technologies, Inc. (DTI), is one of these businesses. DTI has a library of almost one million computer programs that can look at any data it gets. These tools include automated search engines that were developed by its own technicians to speed up the handling of the ten million to 20 million files per week that the company processes. Several claim that there is no way short of physically destroying a hard drive to delete information from it. Several other companies exist, including ASR Data Acquisition \& Analysis which was hired by Arthur Andersen, that perform similar services, each with their own proprietary software.

Several software packages are also available to assist in retrieving destroyed data. These software packages range in price from being free, for example Drive Rescue, to costing hundreds of dollars, for example FinalData Enterprise. These software packages also range in their ability to recover different forms of data and different levels of damaged files.

Drive Rescue finds any lost and deleted data on a drive even if the partition table is lost or the drive has been quickformatted. It can also recover data that has been lost as a result of a system crash. However, it cannot find data on a physically damaged drive. Drive Rescue is a freeware program that supports multiple languages. Its system requirements are Windows 95, 98, ME, NT, 2000, XP, Vista, 7 and 8.

When using Drive Rescue you will be asked to select a language from a provided list. After selecting a language, three choices are provided for retrieving data: Recover Deleted Files, Find Lost Data, and Find Lost Drive. Find Lost Data should be selected if data is lost due to quick-formatting or a system crash. Find Lost Drive should be selected if the drive letter is lost or the drive is inaccessible. After determining and selecting the appropriate retrieval method from the menu, a list of the physical and logical drives available on the system is provided.

From the list of available drives provided by Drive Rescue, a user would select the drive containing the data that needs to be retrieved. The program then searches the selected drive for lost data and displays a list of the files that can be retrieved once a user has located the file that needs to be retrieved, the user would need to right click on the selected file to save it. A drive should be selected from the provided list that does not contain the lost or deleted data to prevent it from being overwritten.

File Recover is another utility program that will scan hard disk drives for any deleted files and help to recover and undelete (unerase) deleted files that are not protected by the standard Windows Recycle Bin or by third-party protection bins. The system requirements for this software package are Windows 95, 98, Me, NT, 2000, XP, Vista, 7. A more recently developed data retrieval software package is File Scavenger, provided by QueTek Consulting Corporation. The system requirements for this software include Windows 10, 8, 7, Vista, Server 2012 and Server 2008. It recovers files damaged by viruses or accidentally deleted from Windows Explorer, the Recycled Bin, the DOS command line, or a network share, along with original folder names and file Create and Modified dates.

FinalData Inc. provides three versions of its software package, FinalData Enterprise. This is a comprehensive software package that recovers files that have been damaged by viruses, formatted, or deleted. It can recover data with removed FAT or directory information. It can even recover files destroyed by $\mathrm{CIH}$, the Worm virus and the Love virus. 
Ontrack offers another comprehensive data retrieval software package, EasyRecovery It uses proprietary data recovery tools. The software recovers files from a wide range of systems: Windows 2000, XP, Vista, 7, 8, 10, and Mac OSX 10.4 or higher. It also recovers files from IDE/ATA/EIDI hard drives, SCSI hard drives, floppy diskettes, Zip and JAZ removable media, and provides advanced data recovery options.

An auditor can use any of these software packages, or others available, to retrieve destroyed data. The choice of a specific method will depend on the type of data destroyed, the nature of the system used, and the auditor's judgment. An important factor affecting the choice of a data retrieval method is the degree to which the auditor believes the destroyed data would affect his judgment. The cost/benefit consideration is another factor. In many cases, the auditor might hire a specialized firm to assist in the retrieval of destroyed electronic data, especially when there is significant damage to the data that requires specialized technical assistance.

\section{CONCLUSION}

The collapse of Enron Corporation has resulted in a furious debate about some practices in the accounting profession. This paper examines three questions of interest that arose as a result of the Enron collapse: First, what is the auditor's ethical responsibility in an audit engagement? Second, in the age of information technology, what is the auditor's responsibility towards the retention and protection of electronic data? Third, when some electronic information is destroyed, how can an auditor retrieve it? The auditor's ethical responsibility has been recognized by the AICPA which issued the Code of Professional Ethics to set standards of ideal conduct and specific rules of conduct. The literature shows that ethical problems in accounting and auditing practices may be attributed to either ethical reasoning or unethical behavior. It is emphasized that compliance with the Code of Professional Ethics is a necessary requirement for the profession to retain the confidence of the public in the services provided.

One of the major issues that emerged from the Enron case is the problem of destroying electronic data related to an audit engagement. This issue has its legal and ethical implications. On one hand, the CPA firm has to have a good retention policy to ensure that documents are gathered, retained, and destroyed in a way that protects the firms from liability. The analysis shows that The Enron's auditors did not comply with the policy. On the other hand, the auditor might bear some responsibility for the lack of a good retention policy at the client. As a result, auditors are now subject to a high risk of litigation. One line of defense for the auditors is to try to retrieve the destroyed electronic data related to the audit engagement. This requires employing some technical methods using specialized software. Several methods to retrieve different types of destroyed electronic data are suggested for use by the auditors.

This paper highlights the need for re-examining the ethical responsibilities of the auditor. It predicts that, in the current information age, auditors are likely to be subject to more litigation, as a result of lacking a good retention policy, and the possibility of destroying electronic data related to audit engagements. This requires additional work to develop more effective and efficient methods to retrieve different types of destroyed electronic data.

\section{AUTHOR BIOGRAPHY}

Mohamed Gomaa is an Assistant Professor of Accounting in the Frank G. Zarb School of Business at Hofstra University, Hempstead, NY. His research interests are in the areas of accounting information systems, and judgment and decision making. He mainly uses experimental psychology and experimental economics methodologies to test the hypotheses of his studies. His research appeared in the International Journal of Accounting Information Systems, Accounting Horizons, the Journal of Behavioral and Experimental Finance, the Journal of Accounting Education, the International Journal of Applied Decision Sciences, Accounting and Finance Research, and Business and Management Review. E-mail: Mohamed.I.Gomaa@hofstra.edu

\section{REFERENCES}

Arthur Andersen, Practice Administration: Client Engagement Information - Organization, Retention and Destruction, Statement No. 760 (February 2000).

Anonymous. (2002). Ex-Enron Says Enron Shredded Documents This Month. Reuters (January 22). 
Au, A. K. M., and D. S. N. Wong. (2000). The Impact of Guanxi on the Ethical Decision-Making Process of Auditors - An Exploratory Study on Chinese CPAs in Hong Kong. Journal of Business Ethics 28: 87-93.

Byrnes, N., M. McNamee, D. Brady, L. Lavelle, and C. Palmeri. (2002). Accounting in Crisis. BusinessWeek Online (January 28).

Castellano, J. (2002). Restoring Public Confidence. Journal of Accountancy. Online Issue (April).

Fernández-Alemán, J. L., I. C. Señor, P. Á. O. Lozoya, and A. Toval. (2013) "Security and Privacy in Electronic Health Records: A Systematic Literature Review." Journal of Biomedical Informatics 46(3): 541-62.

Ferrell, O. C., L. G. Gresham and J. Fraedrich. (1989). A Synthesis of Ethical Decision Models for Marketing. Journal of Macromarketing 9(2): 55-64.

Ford, R. C., and W. D. Richardson. (1994). Ethical Decision Making: A Review of the Empirical Literature. Journal of Business Ethics 13: 205-221.

Gunz, S., and J. McCutcheon. (1991). Some Unresoved Ethical Issues in Auditing. Journal of Business Ethics 10: 777-785.

Hastings, S. O., and H. J. Payne. (2013) "Expressions of Dissent in Email: Qualitative Insights into Uses and Meanings of Organizational Dissent." International Journal of Business Communication 50(3): 309-31.

Herbert, Josef H. (2002). Enron Document Destruction Examined. The Associated Press (January 14).

Hilzenrath, D. S. (2001). Enron's 'Outside” Accountants Also Did Inside Audit. The Washington Post (December 14).

Howell, C. T. (2002). Let the record Stand. Security Management 46(2): 75-80.

Hunton, James E. (2002). Back Up Your Data to Survive a Disaster. Journal of Accountancy. Online Issue (April).

Jones, T. M. (1991). Ethical Decision Making by Individuals in Organizations: An Issue-Contingent Model. Academy of Management Review 16(2): 366-395.

Kolar, R. D. (2001). Prelude: Document Retention in the Electronic Age. FICC Quarterly (Spring): 279-286.

Lampe, J. and D. Finn. (1992). A Model of Auditors' Ethical Decision Process. Auditing: A Journal of Practice and Theory 11: 33-79.

McRoberts, F. D. Alexander, and B. Rose. (2002). Andersen Under Gun to Salvage Lost Data. Chicago Tribune (January 30).

Skupsky, D. S. (1999). Applying Records Retention to Electronic Records. The Information Management Journal 33(3): $28-35$.

Stanford, S. E. (1991). Ethics. The Internal Auditor 48(3): 102-104.

Thomas, C. W. (2002). The Rise and Fall of Enron. Journal of Accountancy. Online Issue (April).

Verschoor, C. C. (2002). Were Enron's Ethical Missteps a Major Cause of Its Downfall? Strategic Finance 83(8): 22-25.

Whittington, R. and G. Fischbach. (2002). The New Audit Documentation Requirements. Journal of Accountancy. Online Issue (April). 
NOTES 